\title{
Espectros de duas formas de lignina obtidos por ressonância magnética nuclear ${ }^{(1)}$
}

\author{
Romualdo Shigueo Fukushima ${ }^{(2)}$ e Ronald Donald Hatfield ${ }^{(3)}$
}

\begin{abstract}
Resumo - O conteúdo de lignina pode ser útil na estimativa da digestão da fibra de plantas forrageiras. A determinação quantitativa da lignina pelo método espectrofotométrico pressupõe a existência de um padrão de referência satisfatório. O objetivo deste trabalho foi avaliar, por meio da ressonância magnética nuclear (RMN), duas ligninas, uma extraída com brometo de acetila ( $\mathrm{LBrAc}$ ) e outra com solução ácida de dioxano (LDiox), para utilização como padrão de referência em análises espectrofotométricas. A ressonância de próton acusou altos teores de carboidratos contaminantes nas amostras de LBrAc. Como a cromatografia líquida já havia indicado menor presença de carboidratos contaminantes na LDiox, os espectros por ressonância de carbono, mais rica em detalhes do que a espectroscopia anterior, porém mais demorada, foram realizados somente nas ligninas LDiox. Este espectro revelou picos típicos, comuns à maioria das ligninas. Os achados da RMN foram condizentes com a análise química, a qual identificou que o carboidrato da parede celular que acompanha a LBrAc seria possivelmente a celulose, ao passo que a pequena contaminação da LDiox teria origem nas pentosanas. A LDiox pode ser considerada melhor padrão de referência para as análises espectrofotométricas do que a LBrAc.
\end{abstract}

Termos para indexação: brometo de acetila, carboidrato, dioxano, parede celular, espectrometria.

\section{Nuclear magnetic resonance spectra of two types of lignin}

\begin{abstract}
Lignin content can be useful to estimate fiber digestion of forage plants. Quantitative determination of lignin by the spectrophotometric method presumes an efficient standard. The objective of this work was to evaluate, by the nuclear magnetic resonance (NMR), two lignins, one extracted with acetyl bromide (AcBrL) and another with acidic dioxane solution (DL), as standards in spectrophotometric analysis. Proton resonance revealed high presence of carbohydrates in the AcBrL residues. Because liquid chromatograph had already shown low contamination with carbohydrates in the DL samples, only carbon resonance, which is lengthier, but richer in details than proton resonance, was run on these lignin samples. The carbon resonance revealed typical peaks common to most lignins. NMR findings were harmonious with wet chemistry which revealed that the cell wall carbohydrates attached to AcBrL would possibly be cellulose whereas in the DL, the small carbohydrate components would come from pentosans. DL can be considered a better standard to the spectrophotometric analysis than AcBrL.
\end{abstract}

Index terms: acetyl bromide, carbohydrates, dioxane, cell walls, spectrometry.

\footnotetext{
(1)Aceito para publicação em 21 de novembro de 2002.

(2) Universidade de São Paulo, Fac. de Medicina Veterinária e Zootecnia, Av. Duque de Caxias Norte, 225, CEP 13630-000 Pirassununga, SP. E-mail: rsfukush@usp.br

(3) United States Department of Agriculture, Agricultural Research Service, Dairy Forage Research Center, 1925 Linden Drive West, Madison, Wisconsin 53706, USA E-mail: rdhatfie@facstaff.wisc.edu
}

\section{Introdução}

A lignina é formada via polimerização de três monômeros fenilpropanóides $\left(\mathrm{C}_{6}-\mathrm{C}_{3}\right)$ e que variam apenas na metoxilação dos carbonos 3 e 5 . São os álcoois p-coumarílico (ausência de grupamentos metoxílicos), coniferílico (metoxilação no $\mathrm{C}_{3}$ ) e 
sinapílico (metoxilação nos $\mathrm{C}_{3}$ e $\mathrm{C}_{5}$ ); ligninas compostas primariamente de álcool coniferílico são denominadas de ligninas guaiacílicas e aquelas formadas predominantemente com álcool sinapil são denominadas de ligninas siringílicas (Buxton et al., 1996). Em uma estrutura arilpropanóide, os carbonos do anel fenólico são identificados com números arábicos, no sentido horário, e os carbonos do segmento propanóide são identificados com as letras gregas $\alpha, \beta$ e $\gamma$, a partir do anel fenólico.

A condensação dessas unidades fenólicas resulta em um polímero extremamente complexo e indigestível para os animais herbívoros (Soest, 1994). Esta substância está presente nas plantas forrageiras em concentrações que geralmente variam de 3\% a $12 \%$ da matéria seca (Jung et al., 1996).

O conteúdo de lignina pode ser útil na estimativa da digestão da fibra (Akin et al., 1977; Jung \& Vogel, 1986); entretanto, qualquer estimador de digestibilidade precisa ser quimicamente determinado com aceitáveis níveis de precisão e acurácia (Faichney, 1975). Entre os vários métodos empregados atualmente na determinação quantitativa da lignina em produtos vegetais, pode-se citar os gravimétricos, tais como a lignina em detergente ácido preconizado por Soest (1963), a lignina permanganato de K de Soest \& Wine (1968) e o tradicional método da lignina Klason (Theander \& Westerlund, 1986).

Outro procedimento analítico, de natureza espectrofotométrica, pode ser empregado com esse mesmo objetivo (Morrison, 1972). Entretanto, todo método espectrofotométrico pressupõe a existência de um padrão de referência com o qual as leituras de densidade óptica possam ser comparadas (Fengel \& Wegener, 1984). Até a presente data, nenhum padrão de referência plenamente satisfatório foi obtido. Recentemente, dois procedimentos para a extração de ligninas foram reportados: um empregando solução de brometo de acetila a $25 \%$ em ácido acético (Fukushima \& Dehority, 2000) e outro no qual a lignina é solubilizada com solução ácida de dioxano (Fukushima \& Hatfield, 2001). O objetivo foi usar essas ligninas como padrões de referência em análises espectrofotométricas, para quantificar os teores de lignina.
Evidentemente que quanto maior o grau de pureza de um padrão de referência, maior será a confiabilidade nos resultados obtidos. A determinação da presença e respectiva quantificação de substâncias contaminantes em um produto novo baseia-se, na maioria das vezes, na química tradicional, que necessariamente deve ter o alvo previamente determinado, e é muitas vezes uma tarefa árdua. A espectroscopia por meio da ressonância magnética nuclear (RMN) é uma ferramenta analítica das mais valiosas para elucidar as estruturas moleculares dos componentes da parede celular, incluindo-se a lignina (Ralph et al., 1994; Ralph, 1998). A RMN também é empregada no estudo de ligninas extraídas (Lu \& Ralph, 1995) e em ligninas sintetizadas em laboratório (Ralph et al., 1995). Destarte, a ressonância magnética nuclear permite direcionar corretamente as ligninas extraídas para a análise química tradicional de substâncias contaminantes.

O objetivo deste trabalho foi avaliar dois tipos de lignina, extraídas sob condições diferentes, por meio da técnica da RMN, na tentativa de se obter subsídios para fundamentar a escolha de uma das duas formas de lignina como padrões de referência em análises espectrofotométricas.

\section{Material e Métodos}

\section{Amostras vegetais}

A alfafa (Medicago sativa L.) e o "bromegrass" (Bromus inermis L.) foram cultivados sob condições controladas de temperatura e regime luminoso, em casa de vegetação pertencente ao United States Department of Agriculture Dairy Forage Research Center (USDA - DFRC), Madison, Wisconsin, EUA. O trevo "kura" (Trifolium ambiguum L.) foi colhido de uma área experimental, localizada na University of Wisconsin Experimental Farm, Arlington, Wisconsin. Amostras de pinheiro (Pinus taeda L.) e álamo (Populus tremuloides L.) foram doações do USDA - Forest Products Laboratory.

No experimento da extração da lignina com o reagente brometo de acetila foram usados a folha e o caule da alfafa, o caule de "bromegrass" e o tronco do pinheiro e do álamo. A alfafa foi colhida no início do florescimento, com cerca de $20 \%$ das flores abertas; "bromegrass", no estádio de emergência da panícula floral; o pinheiro e o álamo, quando apresentavam madeiras maduras. 
No experimento da extração da lignina com solução ácida de dioxano foram utilizados os caules de alfafa, "bromegrass", trevo "kura" e as madeiras do pinheiro e do álamo. O trevo foi colhido no início do florescimento, com cerca de $20 \%$ das flores abertas.

Neste experimento empregaram-se espécies que embora não sejam utilizadas como fonte alimentar para os animais domésticos, suas ligninas não apresentam mudança na composição monomérica dos núcleos aromáticos em relação às ligninas provenientes de plantas forrageiras, a exemplo do álamo.

As plantas forrageiras colhidas foram secadas em estufa a $60^{\circ} \mathrm{C}$ com ventilação forçada e a seguir moídas em moinho laboratorial (Willey), com peneira de $0,5 \mathrm{~mm}$. As amostras de madeiras já vieram sob a forma de serragem e secas. Foi realizado o refluxo seqüencial em aparelho de Soxhlet com água destilada, etanol, clorofórmio e acetona, até que visualmente nenhuma coloração fosse detectada em qualquer dos solventes, o que deu origem à parede celular. Após secadas, as amostras de parede celular foram armazenadas em frascos de vidro.

\section{Extração das ligninas}

A extração da lignina com brometo de acetila ( $\mathrm{LBrAc})$ foi realizada conforme Fukushima \& Dehority (2000). A extração da lignina com dioxano foi feita segundo Fukushima \& Hatfield (2001): 5,0 g de parede celular foram colocados em frasco de fundo redondo $(250 \mathrm{~mL})$ no qual adicionou-se $100 \mathrm{~mL}$ da solução ácida de dioxano $(90 \mathrm{~mL}$ de dioxano $+10 \mathrm{~mL}$ de uma solução $2 \mathrm{~N}$ de $\mathrm{HCl}$ ); o frasco foi conectado a um condensador e gás $\mathrm{N}_{2}$ ventilado sobre a superfície líquida por cerca de 30 segundos. A solução foi, então, refluxada por 30 minutos sob atmosfera de $\mathrm{N}_{2}$. Após resfriamento, a solução foi filtrada a vácuo através de filtro de fibra de vidro (Whatman GF/C, $47 \mathrm{~mm}$ ) e coletada em um frasco erlenmeyer; cerca de $20 \mathrm{~mL}$ de dioxano a $96 \%$ foram empregados para lavar o resíduo sólido. A acidez da solução foi neutralizada com bicarbonato de sódio $(4,0$ a 4,5 g). Em seguida, a solução foi filtrada a vácuo por meio de uma membrana de náilon (diâmetro: $47 \mathrm{~mm}$; porosidade: $0,45 \mu \mathrm{m}$ ) e o volume foi reduzido sob pressão negativa para 15 a $20 \mathrm{~mL}$ em um rotoevaporador, munido com banho-maria regulado a $40^{\circ} \mathrm{C}$. Esta solução concentrada foi, então, gotejada com pipeta pasteur em dois frascos de centrífuga $(250 \mathrm{~mL}$ de capacidade), contendo em cada frasco $200 \mathrm{~mL}$ de água destilada, e rapidamente agitada com o auxílio de um agitador magnético.

O precipitado formado foi separado por centrifugação $\left(9.000 \mathrm{~g}, 15\right.$ minutos, $\left.20^{\circ} \mathrm{C}\right)$; no caso de se formar um precipitado do tipo coloidal, a adição de $2,0 \mathrm{~g}$ de sulfato de sódio anidro (sob agitação) promove a precipitação. O precipitado foi parcialmente desidratado em estufa com ventilação forçada de ar por 20 minutos; este resíduo de lignina foi então dissolvido em 5,0 mL de dioxano (100\%), filtrado através de uma membrana de náilon e adicionado gota a gota em um frasco de centrífuga contendo $200 \mathrm{~mL}$ de éter etílico anidro, rapidamente agitado. Após a floculação, a lignina foi separada do éter por centrifugação $\left(9.000 \mathrm{~g}, 15\right.$ minutos, $\left.5^{\circ} \mathrm{C}\right)$. Esse último passo foi repetido mais duas vezes. Após o descarte do último sobrenadante de solvente orgânico, $80 \mathrm{~mL}$ de éter de petróleo foi adicionado e, com o auxílio de uma espátula, o precipitado foi quebrado em pequenos pedaços. O éter de petróleo foi descartado após a centrifugação. Após secada, a lignina (denominada de lignina dioxano - LDiox) foi armazenada em frasco escuro, com dissecante adequado, no congelador.

\section{Determinação dos carboidratos nas ligninas}

A quantificação dos açúcares neutros foi efetuada após hidrólise das ligninas com solução concentrada de ácido sulfúrico (Hatfield et al., 1994), em um aparelho HPLC, conforme Hatfield \& Weimer (1995) (DX-500 Carbohydrate System usando a coluna Carbopac ${ }^{\mathrm{TM}}$ PA10 $4 \times 250 \mathrm{~mm}$ ). A concentração total de derivados urônicos foi determinada pelo método do fenilfenol (Blumenkrantz \& Asboe-Hansen, 1973).

\section{Ressonância magnética nuclear (RMN)}

Espectroscopias unidimensionais (1D) oriundas de RMN de ${ }^{1} \mathrm{H}$ ou ${ }^{13} \mathrm{C}$ (respectivamente, ressonância de próton ou de carbono) foram registradas em um equipamento Bruker AMX-360 pertencente ao USDA-DFRC. Cada lignina (entre 30 e $40 \mathrm{mg}$, pesada em tubos próprios) foi dissolvida em acetona- $\mathrm{d}_{6} \mathrm{e}$ em seguida mergulhada no campo magnético do equipamento; a aquisição dos espectros durou cerca de seis horas, para a ressonância de próton, e de 20 horas para a ressonância de carbono. Sinais do solvente foram usados como padrão de referência interno.

\section{Resultados e Discussão}

Ao se examinar uma nova substância através da RMN, é recomendável inicialmente a realização de um estudo de caráter exploratório; em relação a ligninas, a aquisição de espectros de ressonância de próton $\left({ }^{1} \mathrm{H}\right)$ é indicada por oferecer picos ainda considerados como de boa definição e num espaço de tempo curto. Espectros com melhor resolução para análise das estruturas moleculares da lignina obtêm- 
se mediante ressonância de carbono $\left({ }^{13} \mathrm{C}\right)$, entretanto o tempo para a aquisição dos picos é maior, tipicamente de 20 a 48 horas.

Para as ligninas extraídas com brometo de acetila, a área correspondente aos picos de carboidratos foi maior do que a área referente aos sinais de hidrogênios aromáticos da lignina, particularmente no caso da lignina proveniente do tecido foliar. A contaminação por carboidratos nas $\mathrm{LBrAc}$ foi de tal magnitude que optou-se por não realizar a integralização dos picos. Essa constatação também foi feita por Fukushima \& Dehority (2000) e Fukushima et al. (2000), via química tradicional, que obtiveram teores elevados de carboidratos variando de $7,3 \%$ a $29,7 \%$ nas $\mathrm{LBrAc}$ de diversas plantas forrageiras. A maior concentração de carboidratos na preparação extraída da folha deve-se à maior atividade metabólica deste tecido, incluindo-se a fotossíntese. Ainda que os carboidratos contaminantes não absorvam a luz ultravioleta na mesma região da lignina $(280 \mathrm{~nm})$ e sua concentração seja contabilizada para efeitos de cálculos da concentração final de lignina, é desejável a obtenção de uma lignina o mais isenta possível de substâncias contaminantes para que possa ser usada como padrão de referência em análises por espectrofotometria. $\mathrm{O}$ espectro da lignina extraída do caule também revelou maior teor de lignina em relação à folha, conforme anteriormente observado (Hatfield et al., 1994).

De significativa importância foi a presença de acetato nas LBrAc. A reação com o brometo de acetila promove extensiva acetilação não só da lignina como dos carboidratos (Lu \& Ralph, 1997a; Iiyama \& Wallis, 1990); embora a acetilação da lignina não contribua na absorção da luz ultravioleta, na pesagem da lignina padrão os grupos acetatos serão responsáveis por substancial contribuição ao peso total (Fukushima \& Hatfield, 2001). No entanto, os grupos acetatos podem ser eficientemente removidos mediante tratamento com solução $2 \mathrm{M}$ de $\mathrm{NaOH}$ por 24 horas, à temperatura ambiente (Morrison \& Stewart, 1995). Ocorrem também reações de brominação (Lu \& Ralph, 1997b), mas as moléculas de bromo podem ser removidas quando as ligninas são suspensas em solução aquosa, que se segue à digestão.
A lignina extraída com solução ácida de dioxano (LDiox) apresentou algumas vantagens sobre a LBrAc, tais como menor contaminação por carboidratos e ausência de grupos de acetato (Fukushima \& Hatfield, 2001). O espectro da RMN da LDiox, pela ressonância de carbono, revelou pequena contaminação por carboidratos. A espectroscopia também mostrou um contaminante, o dioxano, mas a secagem das amostras em liofilizador por 48 horas eliminou o problema.

Quanto aos componentes estruturais da lignina, a RMN revelou picos típicos inerentes à maioria das ligninas conhecidas, tais como as unidades siringílicas e as guaiacílicas, bem como os grupamentos metoxila. A magnitude do pico referente aos radicais metoxila depende do tipo de lignina; por exemplo, na lignina do álamo predominam as unidades siringílicas em relação às guaiacílicas (aproximadamente $2: 1$ ) e os núcleos siringílicos têm grupos metoxilas covalentemente ligados aos carbonos 3 e 5 do anel fenólico, enquanto as unidades guaiacílicas apresentam o grupamento metoxila apenas no $\mathrm{C}_{3}$. Por sua vez, a lignina do pinheiro é constituída essencialmente de unidades guaiacílicas, portanto o pico representando o grupamento metoxila é de menor amplitude.

Os sinais dos carbonos individuais tanto das unidades siringílicas como dos núcleos guaiacílicos também puderam ser detectados nas espectroscopias. A estrutura propanóide, constituída pelos três carbonos não pertencentes ao anel fenólico, denominados de $\gamma, \beta$ e $\alpha$ a contar do carbono funcional, também apareceram na ressonância.

Após detectada presença de carboidratos nas ligninas isoladas, particularmente na $\mathrm{LBrAc}$, a caracterização dos monômeros de açúcares poderia identificar os carboidratos da parede celular que estariam acompanhando as ligninas. Confirmando os espectros obtidos pela RMN, a concentração de açúcares totais na LBrAc proveniente do tecido foliar foi maior do que a do caule da alfafa (Tabela 1). O componente majoritário foi a glicose, inferindo-se a partir dessa observação que o principal carboidrato ligado à $\mathrm{LBrAc}$ seria a celulose. Segundo Hatfield et al. (1999), o reagente brometo de acetila pode rapidamente degradar as xilanas, mas não outros tipos de polissacarídeos da parede celular. 
Tabela 1. Concentração total e individual dos açúcares da lignina brometo de acetila e da lignina dioxano(1).

\begin{tabular}{|c|c|c|c|c|c|c|c|c|c|}
\hline Amostra & $\begin{array}{l}\text { Ácidos } \\
\text { urônicos }\end{array}$ & $\begin{array}{c}\text { Açúcares } \\
\text { neutros }\end{array}$ & Fuc & Ara & Ram & Gal & Gli & Xil & Man \\
\hline & \multicolumn{9}{|c|}{ Lignina brometo de acetila } \\
\hline Alfafa (caule) & 18,8 & 158,6 & 0,0 & 0,0 & 0,4 & 0,4 & 156,5 & 1,3 & 0,0 \\
\hline Alfafa (folha) & 11,7 & 357,5 & 0,0 & 0,4 & 1,3 & 2,0 & 348,5 & 3,2 & 2,0 \\
\hline "Bromegrass" (caule) & 6,0 & 97,7 & 0,0 & 7,7 & 0,0 & 0,0 & 84,6 & 5,4 & 0,0 \\
\hline Pinheiro & 3,7 & 10,7 & 0,0 & 0,0 & 0,0 & 0,0 & 9,4 & 0,0 & 1,3 \\
\hline Média & 10,0 & 156,1 & 0,0 & 2,0 & 0,4 & 0,6 & 149,7 & 2,5 & 0,8 \\
\hline \multirow[t]{2}{*}{ Erro-padrão da média } & 3,37 & 73,66 & 0,00 & 1,89 & 0,31 & 0,48 & 72,74 & 1,17 & 0,50 \\
\hline & \multicolumn{9}{|c|}{ Lignina dioxano } \\
\hline Alfafa & 12,1 & 12,4 & 0,0 & 1,2 & 0,2 & 0,9 & 1,4 & 8,5 & 0,0 \\
\hline "Bromegrass" & 16,7 & 40,3 & 0,0 & 12,2 & 0,0 & 0,5 & 3,2 & 24,4 & 0,0 \\
\hline Trevo "kura" & 16,6 & 35,8 & 0,5 & 6,9 & 1,6 & 4,9 & 5,5 & 15,6 & 0,6 \\
\hline Álamo & 19,4 & 28,2 & 0,0 & 1,4 & 0,5 & 0,9 & 3,8 & 21,4 & 0,0 \\
\hline Pinheiro & 3,7 & 18,6 & 0,0 & 0,9 & 0,0 & 3,2 & 3,6 & 5,1 & 5,6 \\
\hline Média & 13,7 & 27,1 & 0,1 & 4,5 & 0,5 & 2,1 & 3,5 & 15,0 & 1,2 \\
\hline Erro-padrão da média & 2,76 & 5,19 & 0,10 & 2,22 & 0,30 & 0,85 & 0,65 & 3,67 & 1,10 \\
\hline
\end{tabular}

${ }^{(1)}$ Valores são médias de duas observações; Fuc: fucose; Ara: arabinose; Ram: raminose; Gal: galactose; Gli: glicose; Xil: xilose; Man: manose.

Não foi realizada a comparação estatística dos dados, pois o enfoque primário foi a RMN como ferramenta de diagnóstico, e não a comparação de teores de carboidratos entre as amostras vegetais estudadas. A utilização de solução ácida de dioxano para extração e isolamento da lignina priorizou a redução dos teores de carboidratos contaminantes. Quanto à composição de açúcares neutros das LDiox, o componente majoritário foi a xilose, indicativo de que as xilanas estão sendo extraídas com a lignina (Tabela 1). As xilanas são freqüentes componentes de complexos de lignina isolados da parede celular de plantas (Watanabe \& Koshijima, 1988; Kondo et al., 1990). Existem evidências de que glucuronoxilanas são ligadas covalentemente com as ligninas por meio dos resíduos glucuronosil (Watanabe \& Koshijima, 1988), o que explicaria a presença de resíduos de xilose nas LDiox. Com base na composição monomérica dos carboidratos, provavelmente o principal polissacarídeo da LBrAc seria a celulose, que se solubilizaria na solução de brometo de acetila ao ser acetilada (Fukushima \& Hatfield, 2001).

\section{Conclusões}

1. Espectroscopias unidimensionais oriundas de RMN de ${ }^{1} \mathrm{H}$ (ressonância de próton) revelam que as ligninas extraídas com solução de brometo de acetila contêm apreciáveis teores de carboidratos contaminantes, enquanto as ligninas extraídas com dioxano apresentam menor contaminação.

2. Análises cromatográficas indicam que os carboidratos contaminantes da lignina brometo de acetila são resíduos de celulose e que na lignina dioxano há o predomínio de resíduos de pentosanas.

3. As espectroscopias unidimensionais oriundas de RMN de ${ }^{13} \mathrm{C}$ (ressonância de carbono) revelam que as ligninas extraídas com dioxano exibem picos típicos aos encontrados na maioria das ligninas isoladas.

4. A lignina dioxano pode ser considerada melhor padrão de referência para as análises espectrofotométricas do que a lignina brometo de acetila.

\section{Agradecimentos}

À Fundação de Amparo à Pesquisa do Estado de São Paulo (Fapesp), pela bolsa concedida ao primeiro autor.

\section{Referências}

AKIN, D. E.; ROBINSON, E. L.; BARTON, F. E.; HIMMELSBACH, D. S. Change with maturation in anatomy, histochemistry, chemistry and tissue digestibility 
of bermudagrass parts. Journal of Agricultural and Food Chemistry, Washington, v. 25, p. 179-186, 1977.

BLUMENKRANTZ, N.; ASBOE-HANSEN, G. New method for quantitative determination of uronic acids. Analytical Biochemistry, New York, v. 54, p. 484-489, 1973.

BUXTON, D. R.; MERTENS, D. R.; FISHER, D. S Forage quality and ruminant utilization. Agronomy Monography, Madison, v. 34, p. 229-266, 1996.

FAICHNEY, G. J. The use of markers to partition digestion within the gastrointestinal tract of ruminants. In: McDONALD, I. W.; WARNER, A. C. I. (Ed.). Digestion and metabolism in the ruminant. Armidale: University of New England Publishing Unit, 1975. p. 277-291.

FENGEL, D.; WEGENER, G. Wood: chemistry, ultrastructure, reactions. Berlin: W. de Gruyter, 1984. p. 132-191.

FUKUSHIMA, R. S.; DEHORITY, B. A. Feasibility of using lignin isolated from forages by solubilization in acetyl bromide as a standard for lignin analysis. Journal of Animal Science, Savoy, v. 78, p. 3135-3143, 2000.

FUKUSHIMA, R. S.; GARIPPO, G.; HABITANTE, A. M. Q. B.; LACERDA, R. S. Extração da lignina e emprego da mesma em curvas de calibração para a mensuração da lignina em produtos vegetais. Revista Brasileira de Zootecnia, Viçosa, MG, v. 29, p. 1302-1311, 2000.

FUKUSHIMA, R. S.; HATFIELD, R. D. Extraction and isolation of lignin and its utilization as a standard to determine lignin concentration through a spectrophotometric method. Journal of Agricultural and Food Chemistry, Washington, v. 49, p. 3133-3139, 2001.

HATFIELD, R. D.; GRABBER, J.; RALPH, J.; BREI, K. Using the acetyl bromide assay to determine lignin concentrations in herbaceous plants: some cautionary notes. Journal of Agricultural and Food Chemistry, Washington, v. 47, p. 628-632, 1999.

HATFIELD, R. D.; JUNG, H. G.; RALPH, J.; BUXTON, D. R.; WEIMER, P. J. A comparison of the insoluble residues produced by the Klason lignin and acid detergent lignin procedures. Journal of the Science of Food and Agriculture, Chichester, v. 65, p. 51-58, 1994.

HATFIELD, R. D.; WEIMER, P. J. Degradation characteristics of isolated and in situ cell wall lucerne pectic polysaccharides by mixed ruminal microbes. Journal of the Science of Food and Agriculture, Chichester, v. 69, p. 185-196, 1995.
IIYAMA, K.; WALLIS, A. F. A. Determination of lignin in herbaceous plants by an improved acetyl bromide procedure. Journal of the Science of Food and Agriculture, Chichester, v. 51, p. 145-161, 1990.

JUNG, H. G.; BUXTON, D.; HATFIELD, R. D.; MERTENS, D.; RALPH, J.; WEIMER, P. J. Improving forage fiber digestibility. Feed Mix, Doetinchem, v. 4, p. 30-34, 1996.

JUNG, H. G.; VOGEL, K. P. Influence of lignin on digestibility of forage cell wall material. Journal of Animal Science, Savoy, v. 62, p. 1703-1712, 1986.

KONDO, T.; HIROI, T.; MIZUNO, K.; KATO, T. Characterization of lignin-carbohydrate complexes of Italian ryegrass and alfalfa. Canadian Journal of Plant Science, Ottawa, v. 70, p. 193-201, 1990.

LU, F.; RALPH, J. ${ }^{13} \mathrm{C}$ NMR studies on a new method for lignin characterization. Madison: United States Department of Agriculture, 1995. p. 45-46. (Dairy Forage Research Center. Research Summaries ).

LU, F.; RALPH, J. Derivatization followed by reductive cleavage (DFRC method), a new method for lignin analysis: protocol for analysis of DFRC monomers. Journal of Agricultural and Food Chemistry, Washington, v. 45, p. 2590-2592, 1997a.

LU, F.; RALPH, J. DFRC method for lignin analysis. 1. New method for $\beta$-aryl ether cleavage: lignin model studies. Journal of Agricultural and Food Chemistry, Washington, v. 45, p. 4655-4660, 1997b.

MORRISON, I. M. A semi-micro method for the determination of lignin and its use in predicting the digestibility of forage crops. Journal of the Science of Food and Agriculture, Chichester, v. 23, p. 455-463, 1972.

MORRISON, I. M.; STEWART, D. Determination of lignin in the presence of ester-bound substituted cinnamic acids by a modified acetyl bromide procedure. Journal of the Science of Food and Agriculture, Chichester, v. 69, p. 151-157, 1995.

RALPH, J. 3D NMR experiments for use in cell wall research. Madison: United States Department of Agriculture, 1998. p. 46-50. (Dairy Forage Research Center. Research Summaries).

RALPH, J.; HATFIELD, R. D.; QUIDEAU, S.; HELM, R. F.; GRABBER, J. H.; JUNG, H. G. Pathway of $p$-coumaric acid incorporation into maize lignin as revealed by NMR. Journal of the American Chemical Society, Washington, v. 116, p. 9448-9456, 1994. 
RALPH, J.; ZHANG, Y.; EDE, R. M. Preparation and value of synthetic lignins with NMR-invisible methoxyl groups. Madison: United States Department of Agriculture, 1995. p. 38-40. (Dairy Forage Research Center. Research Summaries).

SOEST, P. J. van. Nutritional ecology of the ruminant. Ithaca: Comstock Publishing Associates/Cornell University Press, 1994. 476 p.

SOEST, P. J. van. Use of detergents in the analysis of fibrous foods. II. A rapid method for the determination of fibre and lignin. Journal of the Association of Official Analytical Chemists, Washington, v. 46, p. 829-835, 1963.
SOEST, P. J. van; WINE, R. H. The determination of lignin and cellulose in acid detergent fiber with permanganate. Journal of the Association of Official Analytical Chemists, Washington, v. 51, p. 780-785, 1968.

THEANDER, O.; WESTERLUND, E. A. Studies on dietary fibre. 3. Improved procedures for analysis on dietary fibre. Journal of Agricultural and Food Chemistry, Washington, v. 34, p. 330-336, 1986.

WATANABE, T.; KOSHIJIMA, T. Evidence for ester linkage between lignin and glucuronic acid in lignin-carbohydrate complexes by DDQ-oxidation. Agricultural and Biological Chemistry, Tokyo, v. 52, p. $2953-2955,1988$. 